\title{
Antibacterial activity of bacteriophages isolated from poultry against Shiga-toxic strains of Esherichia coli isolated from calves
}

\author{
MOHAMMED MIJBAS MOHAMMED ALOMARI, ANNA NOWACZEK*, \\ MARTA DEC*, RENATA URBAN-CHMIEL*
}

\begin{abstract}
University of Al Muthanna, Faculty of Veterinary Medicine, Al Muthanna Province, Samawah, Main Street, 66001, Iraq *Sub-department of Veterinary Prevention and Avian Diseases, Institute of Biological Bases of Animal Diseases, Faculty of Veterinary Medicine, University of Life Sciences, Akademicka 12, 20-033 Lublin, Poland
\end{abstract}

Alomari M. M. M., Nowaczek A., Dec M., Urban-Chmiel R.

\author{
Antibacterial activity of bacteriophages isolated from poultry against Shiga-toxic strains \\ of Escherichia coli isolated from calves
}

\section{Summary}

The aim of the study was to evaluate the antibacterial activity of selected bacteriophages obtained from poultry against selected Shiga-positive Escherichia coli strains isolated from calves under in vitro conditions. Eight bacteriophages of the families Myoviridae and Siphoviridae, isolated from different poultry housing systems in south-eastern Poland, were used in the experiment. Bacteriophage morphology was examined with a transmission electron microscope on negative-stained slides with $2 \%$ silicotungstate. The range of lytic activity against Shiga-toxin-producing strains of E. coli was determined by a plaque assay on double-layer top agar plates. Twelve Shiga-toxin-producing E. coli strains isolated from calves were obtained from the National Veterinary Research Institute in Pulawy (Department of Hygiene of Food of Animal Origin), and nine of our own strains were collected from calves with clinical signs of diarrhoea in the Lublin region. The results obtained showed that the phages specific to $\mathbf{E}$. coli isolated from poultry express strong lytic antibacterial properties against Shiga-positive E. coli isolated from calves. These phages exhibited complete lysis of E. coli strains on double-layer agar plates. This result confirms the lack of a species barrier in the antibacterial activity of bacteriophages, which suggests their usefulness in eliminating E. coli infections in cattle.

Keywords: bacteriophages, E. coli, poultry, calves, diarrhoea

Escherichia coli is the cause of a wide variety of enteric and extraintestinal diseases in animals and the most common cause of diarrhoea in farm animals (8). Most $E$. coli strains in the normal flora of animals are non-pathogenic, but Shiga-toxin-producing E. coli (STEC) in the flora of cattle and other ruminants may be highly pathogenic for humans and animals (23). The pathogenicity of these bacteria is associated with virulence genes encoded by plasmids, bacteriophages, or pathogenicity islands (PAI). These genes include the plasmid-encoded genes for enterotoxins and fimbriae or pili, the phage-encoded genes for Shiga toxins (Stx $1,2)$, and the PAI-encoded genes for the attaching and effacing (AE) lesion in enteropathogenic E. coli (EPEC) and enterohaemorrhagic E. coli (EHEC), as well as the pap, hly, and cnfl genes in uropathogenic E. coli (UPEC) $(10,14,21)$.
The most important problem in many infections is an increase in antibiotic resistance among bacteria. The prevalence of antibiotic-resistant bacteria has become a serious problem in the treatment or control of infection in humans and animals. Antibiotic resistance in bacteria has appeared following a widespread use of antibiotics to treat numerous infections in humans and animals $(4,29)$. For this reason, in many cases, alternative methods are sought for the elimination of pathogens with multi-resistance to commonly used chemotherapeutics.

Phage therapy is presented as an alternative method to antibiotic therapies against bacterial infections. If they are obligate lytic phages or virulent phages, they multiply in the host bacterium and lyse it at the end of the cycle, immediately following the replication of new phage particles. As soon as the cell has been 
destroyed, the new phages can find new hosts. In fact, their replication depends exclusively on the infection of a specific bacterial host and on the utilization of the host's intracellular machinery to translate their own genetic code $(1,3,5,28)$.

Most phages are capable of a complete lysis of the bacterial cell, comprising adsorption, penetration, synthesis of the constituent components of phage lysis of bacterial cells, and release of a mature bacteriophage $(22,31)$. As bacteriophages are present in every kind of environment (water, soil, plants and animals), their acquisition is very easy $(27,30)$.

Many studies have shown the efficacy of bacteriophage therapy against pathogenic bacteria in humans and animals, such as Campylobacter and Salmonella infections $(6,13,20)$, as well as infections of burn wounds and skin caused by Pseudomonas, Staphylococcus, Klebsiella, Proteus, E. coli, Salmonella, Listeria monocytogenes $(7,11,17,25)$ and Pseudomonas plecoglossicida (24).

In experimental therapies, bacteriophages have proven to be an effective tool in controlling diseases in poultry, cattle, sheep, pigs and fish. In ruminants, especially new-born calves and lambs, experiments have confirmed a remarkable efficacy of phage therapy in reducing infections caused by ETEC E. coli strains. Experimental therapies using phages obtained from the housing systems of infected animals significantly reduced the intensity of disease symptoms (diarrhoea and fever) and reduced mortality by about $15-67 \%$ (depending on the type of therapy) (16).

The use of bacteriophages to eliminate pathogens depends on the type of bacteria. Most bacteriophages exhibit activity within a specific species or even serotype of bacteria. Some of them, however, may infect more than one species of bacteria (9).

Given previous research showing that bacteriophages can easily be isolated from many sources for use as an alternative therapy against numerous pathogens with resistance to antibiotics, the aim of the study was to determine the antibacterial activity of selected bacteriophages isolated from poultry against Shiga-toxin-producing $E$. coli strains isolated from calves under in vitro conditions.

\section{Material and methods}

Bacterial strains. These were cultures of 12 Shiga-toxin-producing Escherichia coli strains taken from calves, obtained from Prof. J. Osek of the National Veterinary Research Institute in Puławy (Department of Hygiene of Food of Animal Origin), and 9 of our own strains collected from calves with clinical signs of diarrhoea. The bacteria were isolated on Mac-
Tab. 1. Lytic titres of phages isolated from poultry and specific for $E$. coli used in the study

\begin{tabular}{|c|c|c|}
\hline No. & Phage numbers & Lytic titre pfu/ml \\
\hline 1. & ba3 & $5.6 \times 10^{5}$ \\
\hline 2. & ba4 & $4.8 \times 10^{7}$ \\
\hline 3. & ba6 & $5.2 \times 10^{7}$ \\
\hline. & 106 & $1.92 \times 10^{9}$ \\
\hline 5. & 147 & $6.4 \times 10^{9}$ \\
\hline 6. & 148 & $1.6 \times 10^{5}$ \\
\hline 7. & 294 & $1.2 \times 10^{6}$ \\
\hline 8. & 297 & $3.5 \times 10^{9}$ \\
\hline
\end{tabular}

Conkey agar, TSA and TBX, considered selective media for Escherichia coli.

Bacteriophages. The antibacterial activity of eight selected bacteriophages (ba3, ba4, ba6, 106, 147, 148, 294 and 297) from our own collection, belonging to the families Myoviride and Siphoviridae, was evaluated on the basis of their morphological structure. Lytic titres, evaluated by the dilution method in SM buffer according to Golec et al. (12), are shown in Table 1.

Bacteriophage morphology was examined with a transmission electron microscope on negative-stained slides with $2 \%$ silicotungstate (32). For this procedure, we used $5 \mu 1$ of bacteriophage suspension in TM buffer, examined under an electron microscope (Laboratory of Electron Microscopy, Faculty of Biology, University of Gdansk).

Tab. 2. Lytic activity of phages on $E$. coli strains isolated from calves

\begin{tabular}{|r|c|c|c|c|c|c|c|c|c|}
\hline \multicolumn{7}{|c|}{$\begin{array}{r}\text { E. colistrain } \\
\text { numbers }\end{array}$} & \multicolumn{7}{|c|}{ ba3 } & ba4 & ba6 & 106 & 147 & 148 & 294 & 297 \\
\hline 1 & 6 & - & ++ & - & - & ++ & ++ & ++ & ++ \\
\hline 2 & 10 & - & ++ & - & - & ++ & ++ & ++ & ++ \\
\hline 3 & 16 & - & ++ & ++ & - & ++ & ++ & ++ & ++ \\
4 & 21 & ++ & + & + & - & - & - & - & - \\
\hline 5 & 26 & ++ & ++ & ++ & ++ & ++ & - & - & - \\
6 & 27 & + & + & - & - & + & + & - & - \\
\hline 7 & 29 & ++ & ++ & ++ & ++ & ++ & ++ & ++ & ++ \\
8 & 43 & + & ++ & ++ & + & + & ++ & - & - \\
\hline 9 & 44 & - & - & - & - & - & ++ & - & - \\
10 & 51 & + & - & - & - & - & ++ & + & - \\
\hline 11 & 55 & + & + & + & + & + & + & - & - \\
\hline 12 & C & - & - & - & ++ & ++ & - & + & + \\
\hline 13 & C1 & - & - & - & - & - & - & - & - \\
\hline 14 & C2A & - & - & - & + & + & & + & + \\
\hline 15 & C2B & + & - & - & + & - & - & - & - \\
\hline 16 & $1 \mathrm{DN}$ & + & - & - & - & - & - & - & - \\
\hline 17 & 82771 & - & + & + & - & + & - & + & + \\
\hline 18 & 82772 & + & + & - & - & + & + & + & + \\
\hline 19 & 4126 & + & - & - & - & - & - & - & - \\
\hline 20 & Ref & ++ & ++ & ++ & ++ & ++ & ++ & ++ & ++ \\
\hline
\end{tabular}

Explanations: complete lysis $(++)$, partial lysis with turbidity $(+)$, no lysis $(-)$ 
Detection of antibacterial activity. The range of lytic activity against Shiga-toxin-producing strains of $E$. coli was determined by plaque assay on double-layer top agar plates according to (15). Bottle flasks with $20 \mathrm{ml}$ of LB broth were cultured with $200 \mu 1$ of Escherichia coli bacterial suspension in LB broth and then incubated for $3 \mathrm{~h}$ in a shaker water bath $\left(120 \mathrm{rpm} / 37^{\circ} \mathrm{C}\right)$. After incubation, $1,600 \mu 1$ of $E$. coli bacterial cultures were added to $5 \mathrm{~mL}$ of sterile top agar LB broth (cooled to $45^{\circ} \mathrm{C}$ ) containing $0.7 \%$ agar (Sigma, PL) and $400 \mu \mathrm{CaCl}_{2}$ (POCH, PL). On each plate, only one strain of Shigatoxin-producing $E$. coli was added to the top agar. Then the plates were left for $20 \mathrm{~min}$ at room temperature to solidify, after which $5 \mu$ lof the examined phage suspension was applied to each plate and left for 20 minutes to dry at room temperature. The control consisted of plates containing only E. coli strains suspended in top agar.

The plates were incubated overnight at $37^{\circ} \mathrm{C}$, and the results were scored as a clear zone of complete lysis $(++)$, partial lysis with turbidity $(+)$, or no lysis $(-)(19)$.

\section{Results and discussion}

The results obtained showed that all phages exhibited complete lysis of the Shiga-positive Escherichia coli strains. The broadest lytic spectrum (more than 10 bacterial strains) was shown for phages ba3, ba4, 147, 148 and 294, whereas the weakest lytic activity against eight $E$. coli strains was observed in the case of phages ba6, 106 and 297 (Tab. 2). Complete lysis with a clear zone for more than 6 strains was observed in the case of phages ba4, 147 and 148. Complete lysis for fewer than six E. coli strains
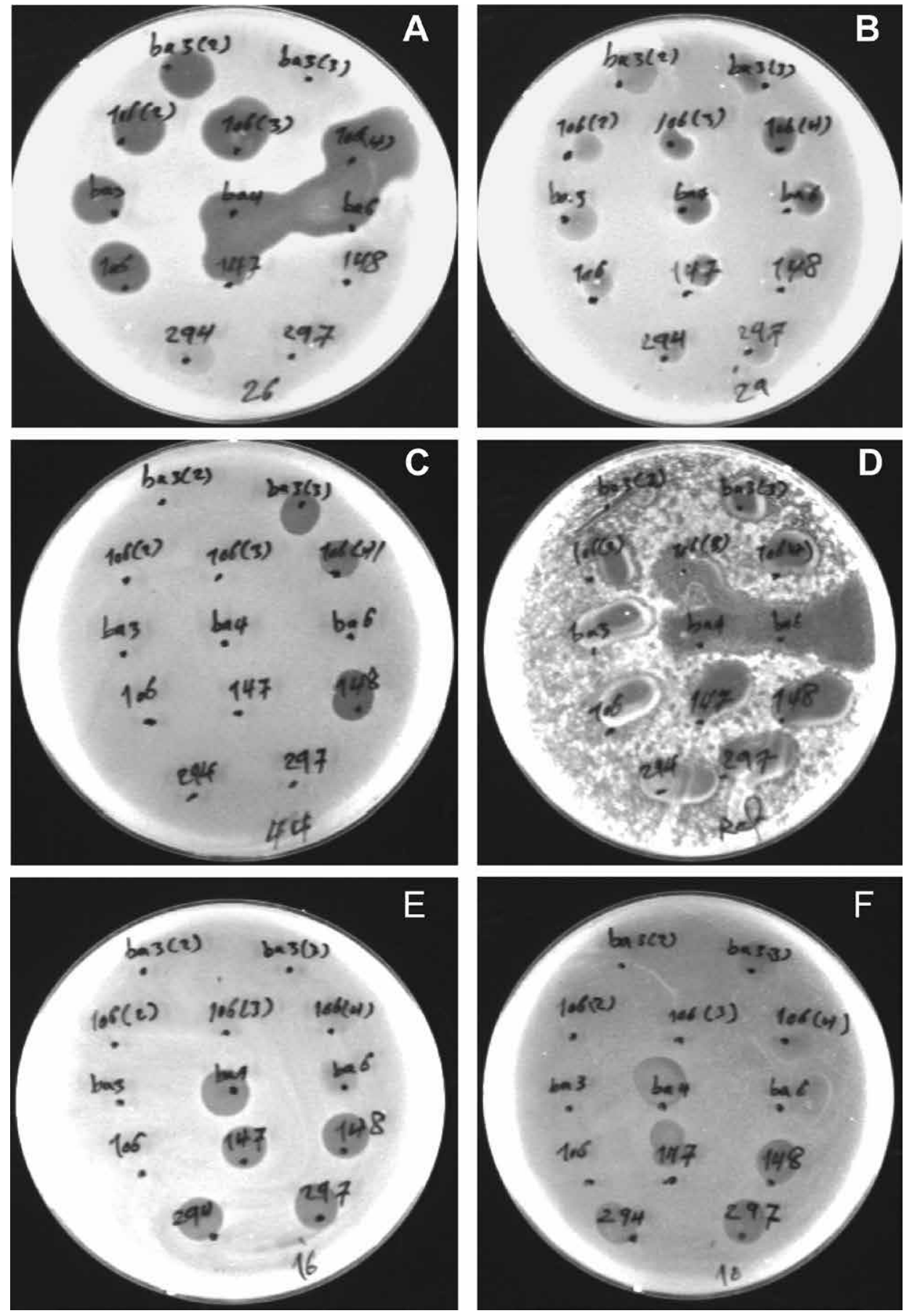

Fig. 1. Lytic zones (plaques) of bacteriophages specific for selected $E$. coli strains Explanations: A - phages ba3, ba4, ba6,106, and 147 on E. coli strain 26; B - phages ba3, ba6, 106, 147,148 and 294 on E. coli strain 29; C - phages ba3, 106 and 148 on E. coli strain 44; D - phages ba3, ba4, ba6, 106, 147, 148, and 294 on E. coli reference (ATCC 8739) strain; E - phages ba4, ba6, 147,148, 294 and 297 on E. coli strain 44; F - phages ba4, 147, 148, 294 and 297 on E. coli strain 10

was observed for phages ba3, ba6, 106, 294 and 297 (Tab. 2). The phages obtained in our study formed different lysis zones, observed as plaque sizes on double top agar plates (Fig. 1). The plaque size was associated with the lytic titre of the bacteriophages and their spectrum of antibacterial activity, which was confirmed in the case of phages ba4, 147 and 297. However, despite the lower titres of lytic phages $\varphi 148$ and $\varphi$ ba4, their spectrum of lytic activity was equally high, and the plaque size was similar to that of the remaining phages.

The present study showed that phages obtained from poultry housing systems and specific to $E$. coli strains isolated from poultry also exhibited strong lytic antibacterial properties against Shiga-positive E. coli obtained from calves. Despite belonging to different families, Myoviridae and Siphoviridae (Fig. 2), all phages showed strong lytic properties against the Shiga-toxin-producing E. coli isolated from calves. These results confirm the lack of a species barrier in the antibacterial activity of bacteriophages. Similar results 

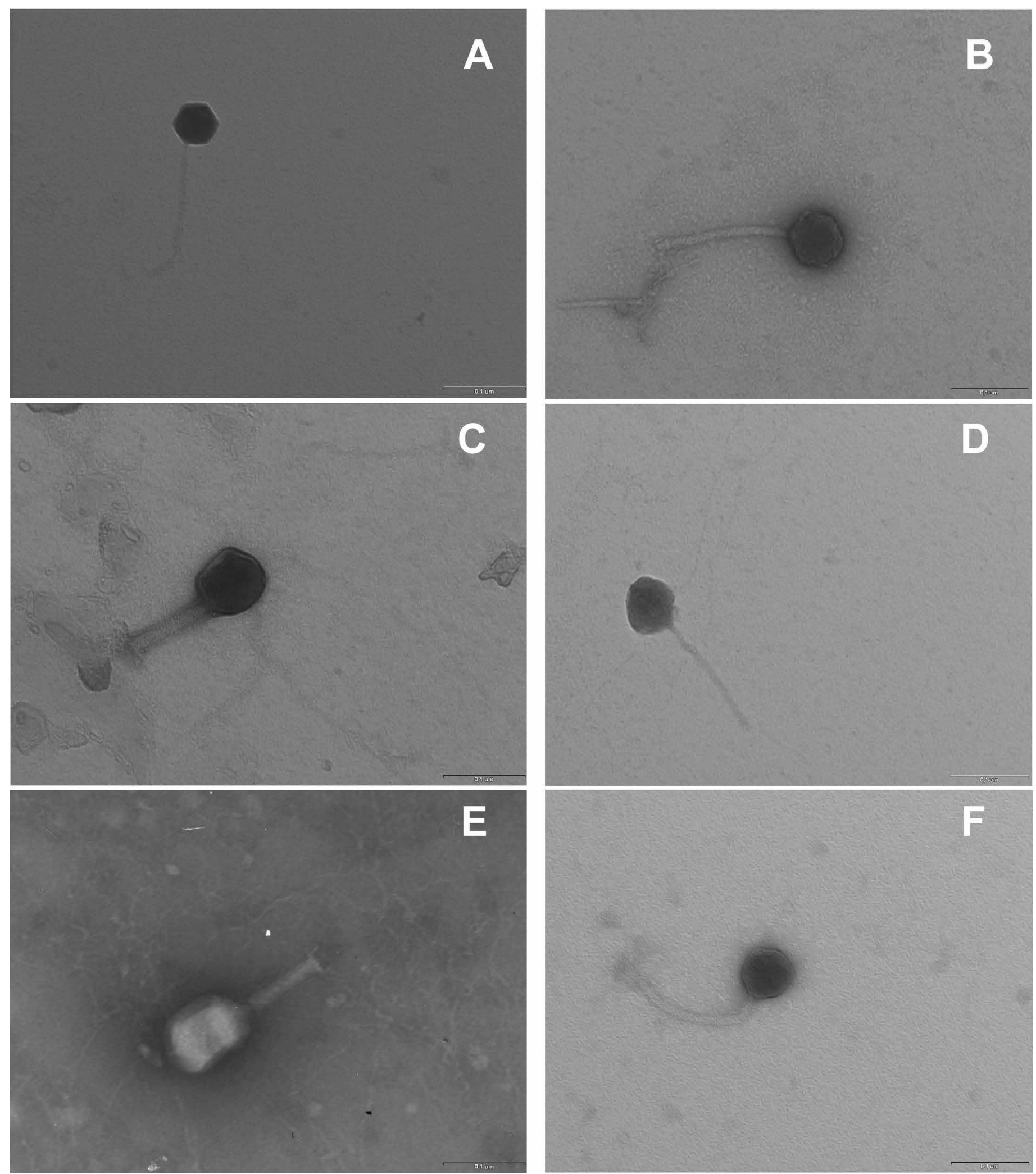

Fig. 2. Negative-stained electron micrographs of selected bacteriophages specific for $E$. coli strains

Explanations: A - Siphoviridae $\varphi$ ba4; B - Myoviridae $\varphi$ ba3; C - Myoviridae $\varphi$ 297; D - Siphoviridae $\varphi 147$; E - Myoviridae $\varphi 106$; F- Siphoviridae $\varphi 148$

were obtained in a study by Barrow et al. (2), who used lytic bacteriophages to control experimental E. coli septicaemia and meningitis in chickens and calves. A great advantage of bacteriophages as an alternative therapy is the development of 'multivalent' phages that lyse all or most of the bacterial strains within a given species of pathogen (5). In another study, bacteriophages isolated from plants (cucumber) exhibited lytic activity against $E$. coli strains isolated from various species, including cattle, humans and vegetables (18).

There are many studies demonstrating the use of bacteriophages in the treatment or control of $E$ coli 
infections in calves, especially those causing diarrhoea. For example, some studies $(16,26)$ showed that calves orally challenged with $E$. coli and given oral doses of bacteriophages 1 or $8 \mathrm{~h}$ after challenge were protected by the bacteriophages against the development of clinical symptoms and death. These studies also confirmed the efficacy of bacteriophages administered in milk in protecting calves against $E$. coli diarrhoea.

The present study showed positive results of phages obtained from poultry in eliminating $E$. coli strains. This suggests a positive factor which increasing the potential of phages in alternative treatment of many infections. This applies in particular to various infections in humans and animals, such as infections of the gastrointestinal tract, respiratory system, skin, etc., caused by microorganisms of the same species or belonging to the same family, which can be eliminated using the same bacteriophage.

The obtained results confirms strong lytic antibacterial properties of phages obtained from poultry against Shiga-positive E. coli isolated from calves. These results show the lack of a species barrier in the antibacterial activity of bacteriophages, which is beneficial in that the same bacteriophages can be used in alternative therapy in humans and animals.

\section{References}

1. Abedon S. T., Herschler T. D., Stopar D.: Bacteriophage latent period evolution as a response to resource availability. Appl. Environ. Microbiol. 2001, 67, 4233-4241.

2. Barrow P., Lovell M., Berchieri Jr A.: Use of lytic bacteriophage for control of experimental Escherichia coli septicemia and meningitis in chickens and calves. Clin. Diagn. Lab. Immunol. 1998, 5, 294-298.

3. Campbell A.: The future of bacteriophage biology. Nat. Rev. Genet. 2003, 46, 471-477.

4. Carl M. S., Jianghong M., Shaohua Z., Chitrita D., Jocelyn T., Cuiwei Z., Patrick F., McDermott M., David D. W., Robert D. W., David G. W.: Antimicrobial Resistance of Escherichia coli O26, O103, O111, O128, and O145 from Animals and Humans. Emerg. Infect. Dis. 2002, 8, 1409-1414.

5. Carlton R. M.: Phage Therapy: Past History and Future Prospects. Arch. Immunol. Therapy Exp. 1999, 47, 267-274.

6. Carrillo L., Atterbury C., El-Shibiny R. J., Connerton A., Dillon P. L., Scott E. A., Connerton I. F.: Bacteriophage therapy to reduce Campylobacter jejun colonization of broiler chickens. Appl. Environ. Microbiol. 2005, 71, 6554$-6563$.

7. Cislo M., Dąbrowski M., Weber-Dąrowska B., Woyton A.: Bacteriophage treatment of suppurative skin infections. Arch. Immunol. Ther. Exp. 1987, 2, 175-183.

8. DebRoy $C$., Maddox $C$. W.: Identification of virulence attributes of gastrointestinal Escherichia coli isolates of veterinary significance. Anim. Health Res. Rev. 2001, 2, 129-140.

9. Engelkirk P. G., Duben-Engelkirk J.: Burton's Microbiology for the Health Sciences. Lippincott Williams \& Wilkins, USA 2009.

10. Franck S. M., Bosworth B. T., Moon H. W.: Multiplex PCR for enterotoxigenic, attaching and effacing, and Shiga toxin producing Escherichia coli strains from calves. J. Clin. Microbiol. 1998, 36, 1795-1797.

11. George S., Vrinda Menon K., Latha C., Sunil B., Sethulekshmi C., Deepa J.: Isolation of Listeria-specific bacteriophage from three different towns in Kerala, India. Int. J. Curr. Microbiol. App. Sci. 2014, 9, 667-669.

12. Golec P., Wiczk A., Loś J. M., Konopa G., Wegrzyn G., Loś M.: Persistence of bacteriophage T4 in a starved Escherichia coli culture: evidence for the presence of phage subpopulations. J. Gen. Virol. 2011, 92, 997-1003.

13. Goode D., Allen V. A., Barrow P. A.: Reduction of experimental Salmonella and Campylobacter contamination of chicken skin by the application of lytic bacteriophages. Appl. Environ. Microbiol. 2003, 69, 5032-5036.
14. Holland R. E., Wilson R. A., Holland M. S., Yuzbasiyan Gurkan V., Mullaney T. P., White D. G.: Characterization of ETEC Escherichia coli isolated from healthy and diarrheic calves. Vet. Microbiol. 1999, 66, 251-263.

15. Huff W. E., Huff G. R., Rath N. C., Balog J. M., Donoghue A. M.: Prevention of Escherichia coli infection in broiler chickens with a bacteriophage aerosol spray. Poultry Sci. 2002, 81, 1486-1491.

16.Johnson R. P., Gyles C. L., Huff W. E., Ojha S., Huff G. R., Rath N. C., Donoghue A. M.: Bacteriophages for prophylaxis and therapy in cattle, poultry and pigs. Anim. Health Res. Rev. 2008, 9, 201-215.

17. Leverentz B., Conway W. S., Camp M. J., Janisiewicz W. J., Abuladze T., Yang M., Saftner R., Sulakvelidze A.: Biocontrol of Listeria monocytogenes on fresh-cut produce by treatment with lytic bacteriophages and a bacteriocin. Appl. Environ. Microbiol. 2003, 69, 4519-4526.

18. Lu Z., Breidt F.: Escherichia coli O157:H7 bacteriophage 241 isolated from an industrial cucumber fermentation at high acidity and salinity. Front Microbiol. 2015, 6, 1-10.

19. Manjunath N. S., Dayanand A., Jagannath K., Rangaswamy B., Chandrasekhar S., Surya Chandra R., Anand S., Yogisha S.: Characterization and in vitro efficacy studies of wide host range lytic bacteriophage DMPAI infecting Pseudomonas aeruginosa isolated from pyogenic skin infection. Trends Biotechnol. Res. 2013, 2, 4-11.

20. Merabishvili M., Pirnay J. P., Verbeken G., Chanishvili N., Tediashvili M., Lashkhi N., Glonti T., Krylov V.: Quality-controlled small-scale production of a well-defined bacteriophage cocktail for use in human clinical trials. PLoS ONE 2009, 4, e4944, doi:10.1371/journal.pone.0004944.

21. Nguyen T. D., Vo T. T., Vu-Khac H.: Virulence factors in Escherichia coli isolated from calves with diarrhea in Vietnam. J. Vet. Sci. 2011, 12, 159-164.

22. O'Flaherty S., Ross R. P., Coffey A.: Bacteriophage and their lysins for elimination of infectious bacteria. FEMS Microbiol. Rev. 2009, 33, 801-819.

23. Osek J., Gallien P., Protz D.: Characterization of Shiga toxin-producing Escherichia coli strains isolated from calves in Poland. Comp. Immunol. Microbiol. Infect. Dis. 2000, 23, 267-276.

24. Park S. C., Nakai T. C.: Bacteriophage control of Pseudomonas plecoglossicida infection in Ayu Plecoglossus altivelis. Dis. Aquat. Organ. 2003, 53, 33-39.

25. Sillankorva S., Pleteneva E., Shaburova O., Santos S., Carvalho C., Azeredo J., Krylov V.: Salmonella Enteritidis bacteriophage candidates for phage therapy of poultry. J. Appl. Microbiol. 2010, 108, 1175-1186.

26. Smith H. W., Huggins M. B.: Effectiveness of phages in treating experimental Escherichia coli diarrhoea in calves, piglets and lambs. J. Gen. Microbiol. 1987, 129, 2659-2675.

27. Suarez V. B., Quiberoni A., Binetti A. G., Reinheimer J. A.: Thermophilic lactic acid bacteria phages isolated from Argentinian dairy industries. J. Food Prot. 2002, 65, 1597-1604.

28. Sulakvelidze A., Alavidze Z., Morris J. J. G.: Bacteriophage therapy. Antimicrob. Agents Chemother. 2001, 45, 649-659.

29. Szmolka A., Nagy B.: Multidrug resistant commensal Escherichia coli in animals and its impact for public health. Front Microbiol. 2013, 4, 258, doi:10.3389/fmicb.2013.00258

30. Tsuei A. C., Carey-Smith G. V., Hudson J. A., Billington C., Heinemann J. A.: Prevalence and numbers of coliphages and Campylobacter jejuni bacteriophages in New Zealand foods. Int. J. Food Microbiol. 2007, 116, 121-125.

31. Weinbauer M. G.: Ecology of prokaryotic viruses. FEMS Microbiol. Rev. 2004, 28, 127-181.

32. Xie H., Zhuang Z., Kong C., Ma G., Zhang H.: Bacteriophage Esc-A is an efficient therapy for Escherichia coli 3-1 caused diarrhea in chickens. J. Gen. Appl. Microbiol. 2005, 51, 159-163.

Corresponding author: dr hab. Renata Urban-Chmiel, prof. nadzw. UP Lublin, ul. Akademicka 12, 20-033 Lublin, Poland; e-mail: renata.urban@ up.lublin.pl 